\title{
The Interaction of Src Kinase with $\beta 3$ Integrin Tails: A Potential Therapeutic Target in Thrombosis and Cancer
}

\author{
Stephan Huveneers ${ }^{1}$ and Erik H.J. Danen ${ }^{2}$ \\ ${ }^{1}$ Dynamics of Cell Adhesion, Hubrecht Institute and University Medical Centre \\ Utrecht, The Netherlands; ${ }^{2}$ Division of Toxicology, Leiden Amsterdam Center for \\ Drug Research, Leiden University, The Netherlands \\ E-mail: s.huveneers@hubrecht.eu; e.danen@lacdr.leidenuniv.nl
}

Received February 27, 2010; Revised May 2 2010; Accepted May 14, 2010; Published June 15, 2010

Activation of Src family kinases is an important event downstream of integrin adhesion signaling in many cell types. A particularly intriguing connection between an integrin and a Src family kinase was first discovered in platelets, where the selective direct interaction of allb $\beta 3$ integrins with c-Src promotes full kinase activation of c-Src through its local clustering by the cytoplasmic tail of the $\beta 3$ integrin subunit. The same integrin $\beta 3-c-S r c$ interaction not only drives platelet aggregation, but it also promotes the oncogenic potential of c-Src and drives tumor growth by av $\beta 3$-expressing tumor cells, which may explain why increased activity of c-Src and elevated levels of integrin av $\beta 3$ are often found in the same tumor types. Moreover, recent evidence from patient material and in vivo studies strongly indicate that this oncogenic signaling complex, consisting of c-Src and $\alpha v \beta 3$, underlies tumor progression of human tumors. Here, we give an overview of the $\beta 3-c-S r c$ interaction and its implications for signaling in platelets and tumor cells, and we mention the possibilities for therapeutic intervention that is aimed at disrupting the $\beta 3$-c-Src interaction for antithrombotic and anticancer purposes.

KEYWORDS: $\beta 3$ integrin, c-Src, platelet, cancer, therapy

\section{INTRODUCTION}

Cells interact with the extracellular matrix through various adhesion receptors, including integrins. Integrins are heterodimeric transmembrane adhesion receptors that link the extracellular matrix with intracellular signaling molecules. When binding to their ligands, integrins cluster and organize the formation of multiprotein complexes, at sites of adhesion, which propagate signaling cascades towards a range of crucial cellular processes involved in normal tissue function and disease[1,2].

Members of the Src family of tyrosine kinases (SFKs) localize to adhesion complexes where they regulate protein-protein interactions and thereby control adhesion turnover. SFKs also control signaling pathways downstream of integrins involved in cytoskeletal organization[3]. Most SFKs are targeted to integrin adhesion complexes indirectly; for instance, through binding to focal adhesion kinase (FAK) or growth factor receptors. $\mathrm{c}$-Src has also been reported to bind directly to the $\beta$-cytoplasmic tails of $\alpha \mathrm{IIb} \beta 3$ 
and $\alpha v \beta 3$ integrins, which contributes to unfolding and activation of c-Src. Here we describe the cellular functions of this $\beta 3$-c-Src signaling unit, and discuss its importance for platelet function as well as growth and progression of cancer.

\section{INTEGRIN allbß3 SPECIFICALLY ACTIVATES c-SRC TO INDUCE PLATELET SPREADING}

Inactive c-Src is folded in a closed conformation due to two intramolecular interactions: (1) Csk-mediated phosphorylation of the C-terminal tyrosine 530 (pY530) creates a binding site for the SH2 domain, and (2) the proline-rich linker region between the $\mathrm{SH} 2$ and kinase domain binds to the membrane proximal SH3 domain. Release of both interactions opens up the molecule towards a "primed conformation" that can be cross-phosphorylated by other Src molecules on tyrosine 419 in the activation loop of the kinase domain leading to full kinase activity[4]. Functional associations between $\beta 3$ integrins and c-Src have been described[5,6,7]. In platelets, engagement of integrin $\alpha \operatorname{IIb} \beta 3$ by its ligand fibrinogen stimulates cSrc activation, which in turn stimulates Syk-mediated cytoskeletal reorganization and platelet spreading on fibrinogen[8]. Direct binding of c-Src to the $\beta 3$ cytoplasmic tail was first demonstrated biochemically for $\alpha \operatorname{IIb} \beta 3$ in platelets[9]. This involves a selective atypical interaction of the c-Src SH3 domain with the C-terminal YRGT residues of the $\beta 3$ cytoplasmic domain[9]. This interaction competes with the c-Src proline-rich linker region for binding to the c-Src SH3 domain, thereby supporting the primed conformation of c-Src in synergy with interactions that compete with Src pY530 for binding to the Src SH2 domain; for instance, mediated by phosphorylated tyrosines in receptor tyrosine kinase (RTK) cytoplasmic tails. Binding of c-Src to the $\beta 3$ tail appears to be constitutive, suggesting that enhanced priming is ligand independent, but ligand-mediated clustering of $\alpha \operatorname{IIb} \beta 3$ integrins drives the final activation of c-Src by promoting transphosphorylation of tyrosine 419 residues in the Src kinase domain[9]. This direct interaction between $c-S r c$ and $\alpha \operatorname{IIb} \beta 3$ can explain their dual requirement for platelet spreading on fibrinogen: adhesion of activated platelets to fibrinogen induces clustering of $\alpha \operatorname{IIb} \beta 3$ integrins, activation of c-Src, and downstream signaling through Syk, which is responsible for platelet aggregation and thrombus formation.

\section{INTEGRIN avß3 CONTROLS THE ONCOGENIC ACTIVITY OF PRIMED c-SRC TO SUPPORT TUMOR GROWTH}

Increased expression and activation of $\mathrm{c}-\mathrm{Src}$ is associated with poor prognosis in various cancer types[10,11]. In those same types of cancer, increased expression of integrin $\alpha v \beta 3$ is related to tumor growth[12]. Overexpressed RTKs in tumor cells stimulate priming of c-Src by competitive binding to the Src SH2 domain, which weakens the intramolecular SH2-pY530 interaction[13]. We have found that increased expression of $\alpha \mathrm{v} \beta 3$ promotes wild-type c-Src-induced tumor growth in the context of overexpressed epidermal growth factor receptor[14]. We expected that this was due to synergy between RTK interactions with the Src SH2 domain and the described $\beta 3$ interactions with the Src SH3 domain, which would maximize unfolding and priming of c-Src causing oncogenic signaling towards tumor growth. To address this, we investigated the oncogenic properties of a primed mutant of c-Src (SrcY530F), which mimics the primed state induced by overexpression of RTKs, and corresponds to Cterminal mutants of c-Src found in subsets of patients with colon and endometrial cancer[15,16]. By using cells expressing different types of integrins, we discovered that the activity of primed c-Src is strongly augmented upon increased expression of $\alpha v \beta 3$, which drives anchorage-independent growth and subcutaneous tumor growth. In analogy to the $\alpha \mathrm{IIb} \beta 3-\mathrm{c}-\mathrm{Src}$ interaction in platelets, the $\alpha v \beta 3-\mathrm{c}-\mathrm{Src}$ oncogenic interaction required the cytoplasmic terminus of $\beta 3$ and the SH3 domain of c-Src. Notably, the oncogenic potential of primed c-Src could not be supported by $\beta 1$ integrins and RasV12-driven tumor growth was not affected by the absence or presence of $\alpha v \beta 3$, indicating that $c-S r c$ and $\alpha v \beta 3$ form a unique 
oncogenic signaling unit[14]. Thus, integrin $\alpha v \beta 3$ on tumor cells can promote (primed) c-Src activation and tumor growth, perhaps explaining why the expression of these two proteins is associated with poor prognosis, and implicating that interfering with their interaction might be a valuable therapeutic goal.

\section{INTEGRIN $\alpha$ $\beta 3$ AND c-SRC DRIVE TUMOR METASTASIS AND PROGRESSION}

There is a particularly strong correlation between elevated c-Src kinase activity[11,17] and increased levels of integrin $\alpha v \beta 3[12]$ with tumor progression. Increased c-Src activity not only induces tumorigenicity, it also drives dramatic morphological changes that may contribute to tumor progression. We found that primed c-Src equally stimulates the formation of highly dynamic invasion structures, called podosomes, both in cells expressing $\alpha \mathrm{v} \beta 3$ or $\alpha 5 \beta 1$, although podosome distribution is different[18]. In addition, integrin $\alpha v \beta 3$ protects against Src-mediated inhibition of cell spreading. The influence of integrins on the morphological alterations induced by primed c-Src may contribute to tumor invasiveness.

It was recently demonstrated that the oncogenic signaling complex of integrin $\alpha v \beta 3$ and c-Src promotes tumor progression of human pancreatic and breast carcinomas. Expression of integrin $\alpha v \beta 3$ was enriched in human lymph node metastasis compared to the matched primary pancreatic and breast tumors[19]. In accordance with our findings, increased $\alpha v \beta 3$ expression in pancreatic tumor cells induced enhanced primary tumor growth and anchorage-independent growth, which occurred through c-Src recruitment to the $\beta 3$ cytoplasmic domain. This interaction caused c-Src activation and downstream signaling through Crk-associated substrate (CAS). Intriguingly, although adhesion of the pancreatic tumor cells to the extracellular matrix protein fibronectin was mediated through both $\alpha 5 \beta 1$ and $\alpha \mathrm{v} \beta 3$ integrin types, activated Src only colocalized with $\alpha v \beta 3$ integrins. Importantly, silencing of c-Src expression or pharmacological blockade of c-Src activity using dasatinib, but not inhibition of the related protein FAK, inhibited spontaneous metastasis of $\alpha \mathrm{v} \beta 3$-expressing tumor cells. Moreover, reduced expression of $\alpha v \beta 3$, but not blockade of $\alpha v \beta 3$ ligand binding, lowered anchorage-independent growth and metastasis[19].

There is accumulating evidence for a role of the $\alpha \mathrm{v} \beta 3$ and c-Src complex in tumor progression of other cancers. For instance, expression of high-affinity state integrin $\alpha v \beta 3$ supported growth of metastatic brain tumors by a strong induction of VEGF production and tumor angiogenesis[20]. Although this still has to be investigated thoroughly, the enhanced effect on tumor metastasis by activated $\alpha \mathrm{v} \beta 3$ may well occur through oncogenic signaling through the $\beta 3$-c-Src oncogenic complex, as activation of platelet integrin $\alpha \operatorname{Ilb} \beta 3$ is indeed associated with increased activation of c-Src[8]. Another example comes from analysis of different melanoma cell types. Expression of integrin $\alpha v \beta 3$ alone in melanoma cells turned out to be insufficient to support invasion of melanoma cells; instead, elevation of c-Src activity was strictly required to support $\alpha \mathrm{v} \beta 3$-mediated invasion[21].

Together, these studies indicate that the selective interaction of $\beta 3$ and c-Src may be a very potent therapeutic target to treat tumor growth, invasion, and metastasis.

\section{MODEL OF SRC ACTIVATION BY $\beta 3$ INTEGRINS}

The following c-Src activation model by $\beta 3$ integrins can be proposed (Fig. 1): c-Src in unstimulated cells is maintained in an inactive conformation through Csk-mediated phosphorylation of tyrosine 530, and through SH2- and SH3-mediated intramolecular interactions. The cytoplasmic tails of $\beta 3$ integrins bind constitutively and selectively to the SH3 domain of c-Src, creating a pool of Src molecules that are partly primed. Whether this interaction promotes more extensive conformational changes and leads to the recruitment of additional proteins that contribute to c-Src activation is unclear. Other events, for instance, Csk inactivation and/or competitive SH2-mediated interactions with pY530, are required to disrupt the SH2-pY530 intramolecular interaction, thereby contributing to further priming. However, the interaction with the $\beta 3$ cytoplasmic tail is critical for full c-Src activation, since activation of a SrcY530F mutant still depends on integrin $\alpha v \beta 3$ for its activity, despite the fact that autoinhibition of pY530 with the SH2 


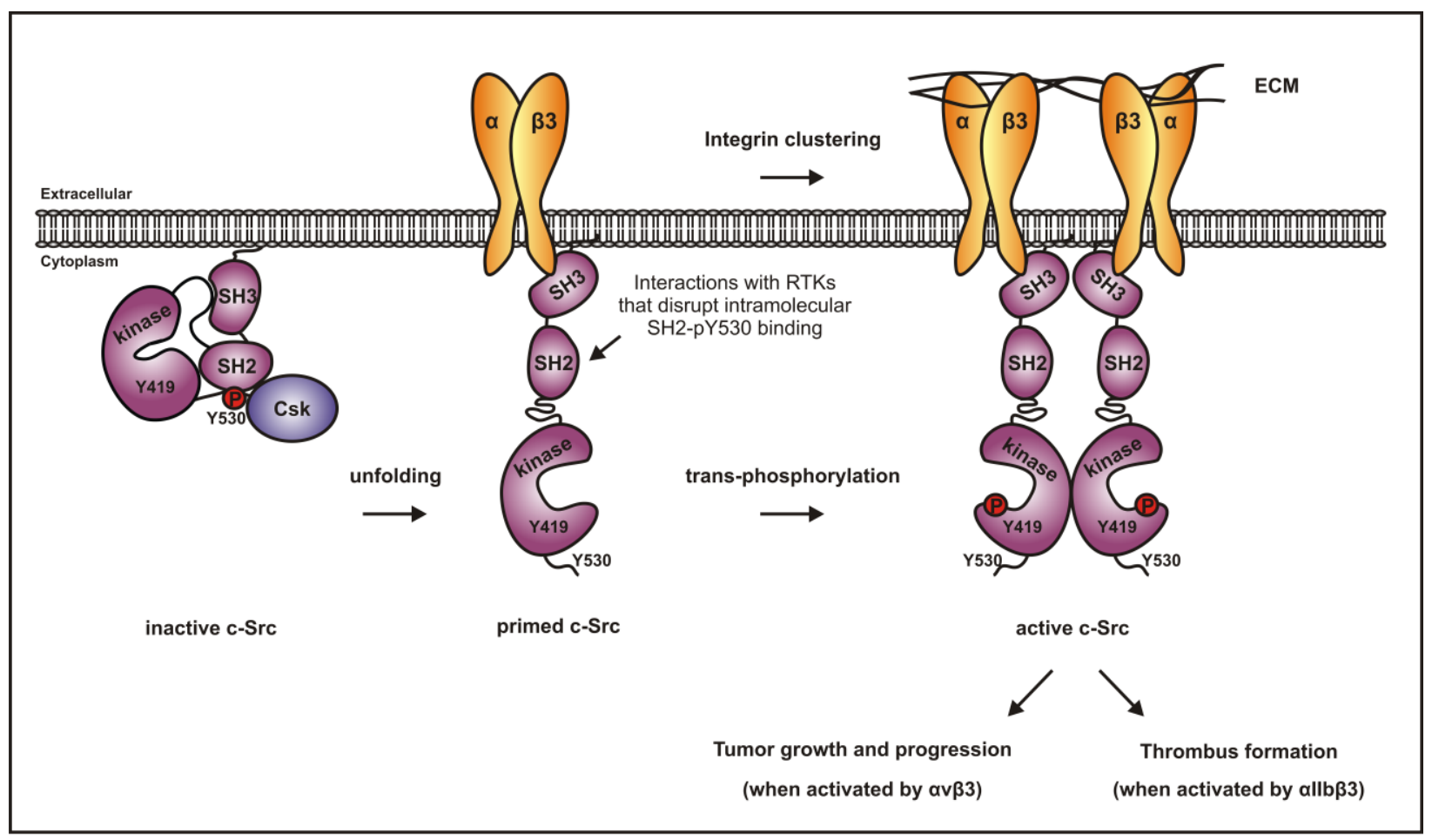

FIGURE 1. Model of c-Src activation by $\beta 3$ integrins.

domain is abrogated. As a final step, ligand-mediated clustering of $\beta 3$ integrins may promote full activation of c-Src through transphosphorylation of the c-Src kinase domain.

In platelets, activation of c-Src by $\alpha \operatorname{IIb} \beta 3$ requires fibrinogen-mediated clustering[22]. Our findings with c-Src in the context of overexpressed RTKs or primed SrcY530F mutants, and the results from Desgrosellier and colleagues investigating $\mathrm{c}-\mathrm{Src}$ in pancreatic cancer cells, indicate that $\alpha v \beta 3$ integrin can support the oncogenic potential of c-Src in an anchorage-independent way[14,19]. However, a role for ligand-induced activation of integrins in the activation of c-Src cannot be excluded, and ligands in solution or trapped between cells may play a critical role in these experimental setups. On the other hand, the $\beta 3$ integrin subunit has been reported to have a tendency to form homo-oligomers in the plane of the plasma membrane, providing a possible ligand-independent mechanism for c-Src clustering[23].

\section{THE BINDING INTERFACE OF $\beta 3$ AND c-SRC AS A PROMISING THERAPEUTIC TARGET}

In vitro experiments and preclinical models show promising effects of $\mathrm{c}-\mathrm{Src}$ as a therapeutic target to inhibit tumor growth and progression, and several Src inhibitors are currently being tested in clinical trials[24]. Similarly, integrin antagonists may be valuable as adjuvants to increase the efficacy of radioand chemotherapy[25]. The discovery of the importance of the direct interaction of $\alpha v \beta 3$ and c-Src for tumor growth and progression raises the opportunity for the development of highly specific inhibitors for tumor types in which $\alpha v \beta 3$ levels and c-Src activity are elevated. The C-terminal RGT residues of the $\beta 3$ cytoplasmic domain and the SH3 domain of c-Src might form the basis of the development of such $\beta 3$-cSrc-specific inhibitors. Again, much might be learned from studies in platelets, as it was recently found that a cell-permeable and membrane-targeted RGT peptide indeed prevents the interaction of $\alpha$ IIb $\beta 3$ and c-Src in human platelets, thereby lowering c-Src activation and platelet spreading on fibrinogen, 
indicating that this peptide may be a promising antithrombotic agent[26]. In analogy, we propose that such a developed drug targeted to tumor cells may also be useful for treatment of cancer.

\section{ACKNOWLEDGMENTS}

The work of SH and EHJD is supported by the Dutch Cancer Society (grants UL2006-3521 and UL20073860).

\section{REFERENCES}

1. Hynes, R.O. (2002) Integrins: bidirectional, allosteric signaling machines. Cell 110, 673-687.

2. Danen, E.H. and Sonnenberg, A. (2003) Integrins in regulation of tissue development and function. J. Pathol. 201, 632-641.

3. Huveneers, S. and Danen, E.H. (2009). Adhesion signaling - crosstalk between integrins, Src and Rho. J. Cell Sci. 122, 1059-1069.

4. Martin, G.S. (2001) The hunting of the Src. Nat. Rev. Mol. Cell Biol. 2, 467-475.

5. Soriano, P., Montgomery, C., Geske, R., and Bradley, A. (1991) Targeted disruption of the c-src proto-oncogene leads to osteopetrosis in mice. Cell 64, 693-702.

6. $\quad$ Felsenfeld, D.P., Schwartzberg, P.L., Venegas, A., Tse, R., and Sheetz, M.P. (1999) Selective regulation of integrin-cytoskeleton interactions by the tyrosine kinase Src. Nat. Cell Biol. 1, 200-206.

7. McHugh, K.P., Hodivala-Dilke, K., Zheng, M.H., Namba, N., Lam, J., Novack, D., Feng, X., Ross, F.P., Hynes, R.O., and Teitelbaum, S.L. (2000) Mice lacking beta3 integrins are osteosclerotic because of dysfunctional osteoclasts. $J$. Clin. Invest 105, 433-440.

8. $\quad$ Obergfell, A., Eto, K., Mocsai, A., Buensuceso, C., Moores, S.L., Brugge, J.S., Lowell, C.A., and Shattil, S.J. (2002) Coordinate interactions of Csk, Src, and Syk kinases with [alpha]IIb[beta]3 initiate integrin signaling to the cytoskeleton. J. Cell Biol. 157, 265-275.

9. Arias-Salgado, E.G., Lizano, S., Sarkar, S., Brugge, J.S., Ginsberg, M.H., and Shattil, S.J. (2003) Src kinase activation by direct interaction with the integrin beta cytoplasmic domain. Proc. Natl. Acad. Sci. U. S. A. 100, 1329813302 .

10. Irby, R.B. and Yeatman, T.J. (2000) Role of Src expression and activation in human cancer. Oncogene 19, 56365642.

11. Summy, J.M. and Gallick, G.E. (2003) Src family kinases in tumor progression and metastasis. Cancer Metastasis Rev. 22, 337-358.

12. Mizejewski, G.J. (1999) Role of integrins in cancer: survey of expression patterns. Proc. Soc. Exp. Biol. Med. 222, 124-138.

13. Thomas, S.M. and Brugge, J.S. (1997) Cellular functions regulated by Src family kinases. Annu. Rev. Cell Dev. Biol. 13, 513-609.

14. Huveneers, S., van den Bout, I., Sonneveld, P., Sancho, A., Sonnenberg, A., and Danen, E.H. (2007) Integrin alpha v beta 3 controls activity and oncogenic potential of primed c-Src. Cancer Res. 67, 2693-2700.

15. Irby, R.B., Mao, W., Coppola, D., Kang, J., Loubeau, J.M., Trudeau, W., Karl, R., Fujita, D.J., Jove, R., and Yeatman, T.J. (1999) Activating SRC mutation in a subset of advanced human colon cancers. Nat. Genet. 21, 187190.

16. Sugimura, M., Kobayashi, K., Sagae, S., Nishioka, Y., Ishioka, S., Terasawa, K., Tokino, T., and Kudo, R. (2000) Mutation of the SRC gene in endometrial carcinoma. Jpn. J. Cancer Res. 91, 395-398.

17. Frame, M.C., Fincham, V.J., Carragher, N.O., and Wyke, J.A. (2002) v-Src's hold over actin and cell adhesions. Nat. Rev. Mol. Cell Biol. 3, 233-245.

18. Huveneers, S., Arslan, S., van de Water, B., Sonnenberg, A., and Danen, E.H. (2008) Integrins uncouple Src-induced morphological and oncogenic transformation. J. Biol. Chem. 283, 13243-13251.

19. Desgrosellier, J.S., Barnes, L.A., Shields, D.J., Huang, M., Lau, S.K., Prevost, N., Tarin, D., Shattil, S.J., and Cheresh, D.A. (2009) An integrin alpha(v)beta(3)-c-Src oncogenic unit promotes anchorage-independence and tumor progression. Nat. Med. 15, 1163-1169.

20. Lorger, M., Krueger, J.S., O'Neal, M., Staflin, K., and Felding-Habermann, B. (2009) Activation of tumor cell integrin alphavbeta3 controls angiogenesis and metastatic growth in the brain. Proc. Natl. Acad. Sci. U. S. A. 106, 10666-10671.

21. Putnam, A.J., Schulz, V.V., Freiter, E.M., Bill, H.M., and Miranti, C.K. (2009) Src, PKCalpha, and PKCdelta are required for alphavbeta3 integrin-mediated metastatic melanoma invasion. Cell Commun. Signal. 7, 10.

22. Shattil, S.J. (2005) Integrins and Src: dynamic duo of adhesion signaling. Trends Cell Biol. 15, 399-403. 
23. Li, R., Mitra, N., Gratkowski, H., Vilaire, G., Litvinov, R., Nagasami, C., Weisel, J.W., Lear, J.D., Degrado, W.F., and Bennett, J.S. (2003) Activation of integrin alphaIlbbeta3 by modulation of transmembrane helix associations. Science 300, 795-798.

24. Hiscox, S. and Nicholson, R.I. (2008) Src inhibitors in breast cancer therapy. Expert Opin. Ther. Targets 12, 757767.

25. Huveneers, S., Truong, H., and Danen, E.H. (2007) Integrins: signaling, disease, and therapy. Int. J. Radiat. Biol. 83, $743-751$.

26. Su, X., Mi, J., Yan, J., Flevaris, P., Lu, Y., Liu, H., Ruan, Z., Wang, X., Kieffer, N., Chen, S., et al. (2008) RGT, a synthetic peptide corresponding to the integrin beta 3 cytoplasmic C-terminal sequence, selectively inhibits outside-in signaling in human platelets by disrupting the interaction of integrin alpha IIb beta 3 with Src kinase. Blood 112, 592602.

\section{This article should be cited as follows:}

Huveneers, S. and Danen, E.H.J. (2010) The interaction of Src kinase with $\beta 3$ integrin tails: a potential therapeutic target in thrombosis and cancer. TheScientificWorldJOURNAL 10, 1100-1106. DOI 10.1100/tsw.2010.114. 

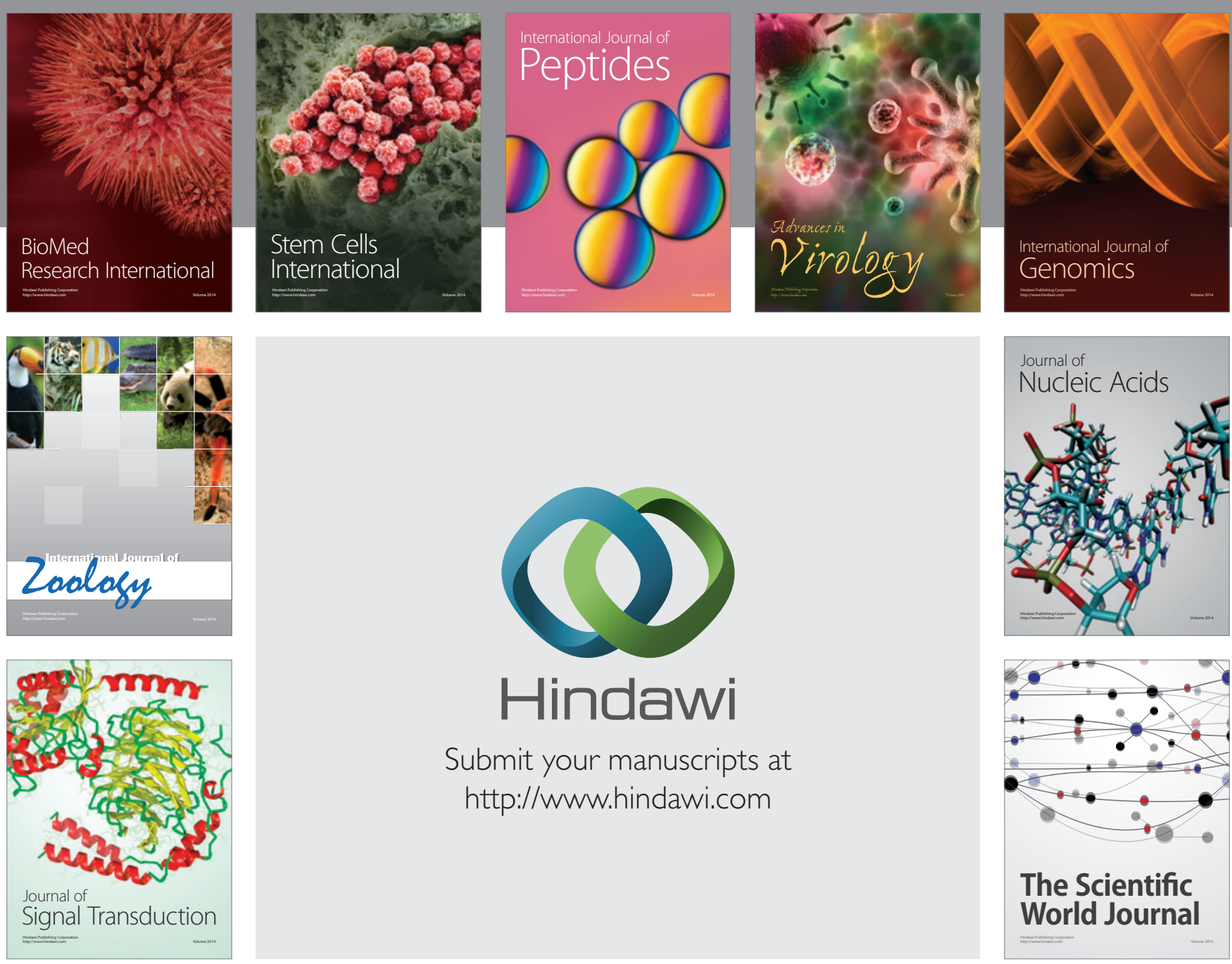

Submit your manuscripts at

http://www.hindawi.com
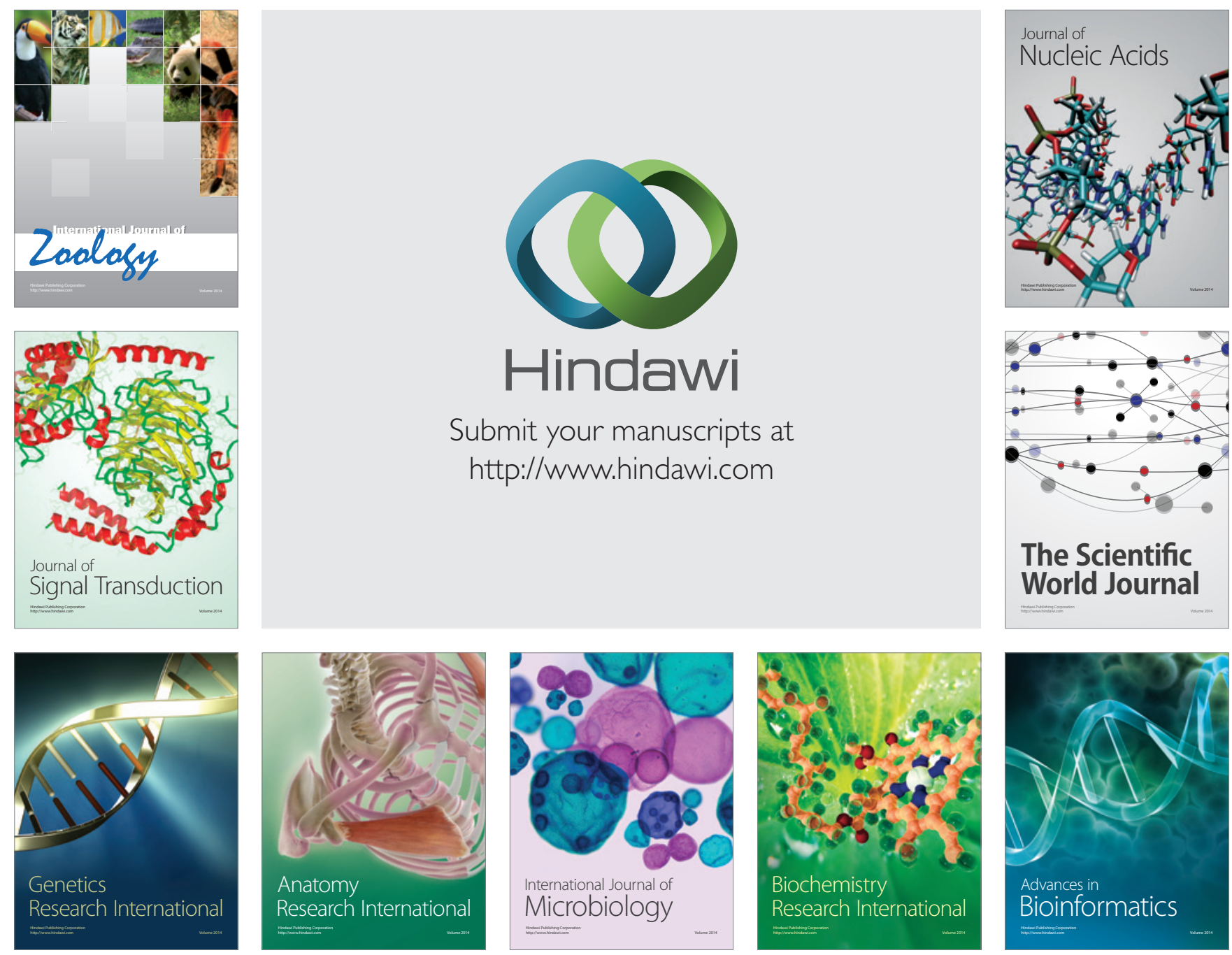

The Scientific World Journal
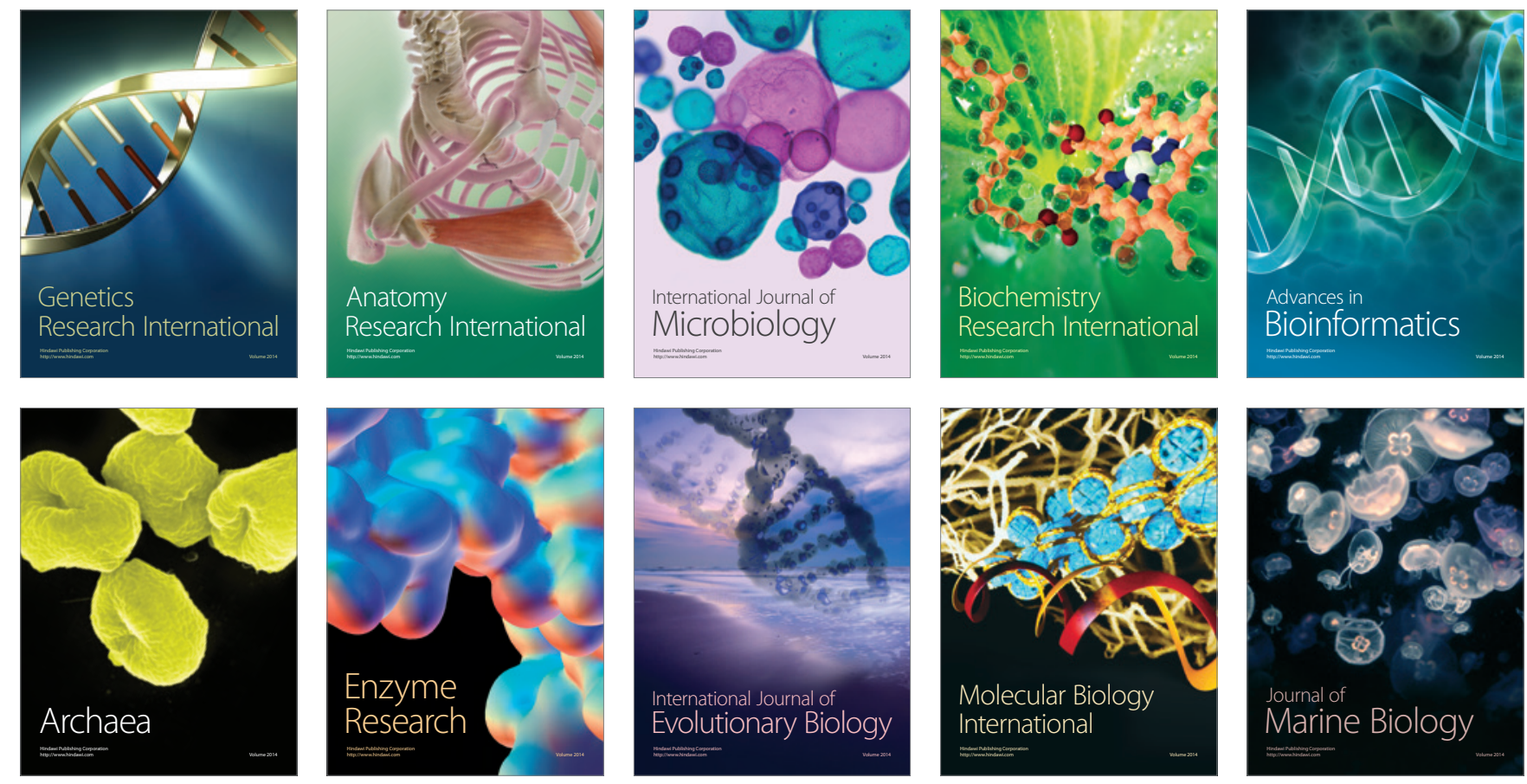